\section{Effect of Recess on Fifth Grade Students' \\ Time On-task in an Elementary Classroom}

$\begin{array}{ll}\text { Received: } & 28 \text { November } 2017 \\ \text { Revised: } \quad 20 \text { February } 2018 \\ \text { Accepted: } \quad 28 \text { February } 2018 \\ \text { ISSN: } 1307-9298 \\ \text { Copyright (C) IEJEE } \\ \text { www.iejee.com }\end{array}$

\author{
Alicia Cooper Stapp ${ }^{a, *}$, Jenny Kate Karr ${ }^{b}$
}

DOI: 10.26822/iejee.2018438135

\begin{abstract}
Recess is an integral part of the school day where children are afforded the opportunity to create and organize games, socialize with their peers, and explore nature. When implemented effectively, recess has the potential to offer significant academic, physical, and social benefits (London, Westrich, Stokes-Guinan, \& McGlaughlin, 2015). However, the amount of time allocated to recess in elementary schools across the United States has significantly declined over the past two decades. A reduction in play time can be attributed to increased educational mandates, which have lead to vigorous and ongoing debates about the important role recess plays in elementary schools. Thus, this quantitative study examined the effect of recess on fifth grade students' time on-task in an elementary classroom. Participants on- and off-task behaviors were observed and documented on a task frequency chart prior to and after recess. Findings from the study indicated that providing fifth-grade students with daily recess significantly increased on-task behaviors in the classroom.
\end{abstract}

Keywords: Recess, time on-task, elementary classroom, instructional time

\section{Introduction}

Expanding learning time policies is increasingly popular in educational reform across the United States. Subsequently, academic instruction occupies most of a child's school day with the underlying goal of increasing academic performance (Woods, 2015). This reallocation of time during the school day to address academic concerns is not fading; if anything, the trend is increasing. In the Pennsylvania State Education Association's (PSEA) 20/20 Vision for the Future (2010), authors note that increasing instructional time is critical to improving student achievement. However, critics argue that a change in instructional time does not have a significant impact on student achievement and can be a catalyst for behavior problems (Baker, Febrega, Galindo, \& Mishook, 2004; Silva, 2007). To combat long periods of instruction, a number of countries embed unstructured recess breaks throughout the school day with the understanding that providing physical activity improves attentiveness in the classroom (Pelligrini \& Bohn, 2005). This strategy is scarcely practiced in the United States, as the foci remains steadfast on increasing academic achievement. Therefore, breaks from academic instruction, such as recess, remain at a high risk of being diminished or eliminated altogether (Ramstetter, Murray, \& Garner, 2010).

\section{Decrease in recess time}

The Center on Education Policy (2008) examined the impact of the No Child Left Behind (NCLB) Act on recess and found that $20 \%$ of school districts decreased recess time, with an average decrease of 50 minutes per week (Center on Education Policy, 2008). Burriss and Burriss (2011) examined the effect of policy and practice on outdoor play and learning via questionnaires. The surveys completed by representatives from 173 randomly selected school districts in the United States indicated that $32.3 \%$ of respondents believed that there had been a decrease in time for outdoor play and only $5.3 \%$ believed there had been an increase (Burriss \& Burriss, 2011). These reductions allocate more time for English and math instruction (Brusseau \& Hannon, 2015).

Although the Every Student Succeeds Act (ESSA) of 2015 requires that Health and Physical Education curricula be included as part of a child's well-rounded education, it does not mandate time for recess or outdoor play. Ultimately, the decision to implement or remove recess is at the discretion of each state, school district, or individual school. Without daily recess, students find themselves in sedentary environments a majority of the school day. The effects of such sedentary behaviors can be detrimental to students' physical activity levels, social development, and academic achievement (McManus et al., 2015).

Time on-task

An extensive body of research has examined how recess affects students' social (Barros, Silver, \& Stein, 2009; Jarrett, 2002; Ramstetter et al., 2010), physical (Erwin, Ickes, Ahn, \& Fedewa, 2014; Ling, King, Speck, Kim, \& Wu, 2014; Springer, Tanguturi, Ranjit, Skala, \& Kelder, 2013), and academic abilities (Brusseau \& Hannon, 2015; Chang \& Coward, 2015; Pelligrini \& Bohn, 2005). However, few studies have examined the effect recess has on students' time on-task in the classroom, prior to and following a period of recess. According to Karweit and Slavin (1981), the amount of time that students spend on-task, or engaged in learning, is an important factor contributing to academic achievement. In classrooms where students spend limited amounts of time on-task, a vast amount of instructional time is lost. Conversely, a greater amount of instructional time is displayed in classrooms where students spend a majority of time on-task (Karweit \& Slavin, 1981). Furthermore, a beginning teacher evaluation study indicated that students who spend more time engaged in the learning process have higher levels of academic achievement (Berliner \& Tukinoff, 1976). Thus, it is imperative for elementary classroom teachers to utilize methods and strategies such as physical breaks from the classroom that may help increase time on-task.

\footnotetext{
${ }^{a, *}$ Correponding Author: Alicia Cooper Stapp, School of Education, Department of Teacher Education, University of Mississippi, USA.

E-mail:acstapp@olemiss.edu

b Jenny Kate Karr, School of Education, Department of Teacher Education, University of Mississippi, USA. E-mail:jksmith2@go.olemiss.edu
} 


\section{Effect of recess on social development}

While the academic and physical benefits of recess are perhaps the most documented factors that can be used to advocate for increased recess time for children, recess has the multifaceted potential to affect the whole child in ways that exceed academic and physical benefits (Ramstetter et al., 2010). In direct contrast to classroom activities where children cannot make the choice to withdraw from an activity, at recess, children are free to join in or leave play situations according to their own discretion. This "open setting" that children encounter at recess enables them to engage in diverse and abundant social interactions that they may not experience otherwise (Jarrett, 2002, p. 3). Additionally, this open and unstructured recess period provides time for children to acquire social skills that may not be developed within a structured classroom environment (Ramstetter et al., 2010).

\section{Effect of recess on academic achievement}

Research suggests that social interactions have important cognitive implications. However, the opportunity for communication with peers is not the only aspect of recess that benefits students' academic achievement (Pellegrin \& Smith, 1993). Elementary students in Shanghai, China receive daily recess time that amounts to almost $40 \%$ of an entire school day. Even though these students spend more time away from academic work every day, their ability to perform well on academic tasks has not declined. In fact, these are some of the world's highest achieving students, and they repeatedly receive top honors in multiple areas on the Program for International Student Assessment, the "most-watched international comparison exam" (Chang \& Coward, 2015, p. 15).

Donnelly and Lambourne (2011) examined the effect of providing "90 min/week of moderate to vigorous physically active academic lessons intermittently throughout the school day" (p. S38) on the academic achievement of students in 24 elementary schools in northeast Kansas. A third party of trained psychologists measured academic achievement by administering The Wechler Individual Achievement Test. This test assesses reading, writing, mathematics, spelling, and oral language skills. Performance on this standardized test indicated an improvement of $6 \%$ among students involved in physically active academic lessons compared to a $1 \%$ decrease for students in control classrooms. Thus, concluding that physical activity can have a positive impact on academic achievement (Donnelly \& Lambourne, 2011).

\section{Effect of recess on childhood obesity}

Increasing elementary children's physical activity levels at school is also an essential element to reducing childhood obesity (Chin \& Ludwig, 2013). Obesity is an increasingly present issue among elementary school age children across the globe. A national report, Prevalence of Obesity Among Children and Adolescents: United States, Trends 1963-1965 Through 2007-2008, indicated that the prevalence of childhood obesity has tripled since 1976, when only $6.5 \%$ of children ages 6-11 were classified as obese (Ogden \& Carroll, 2010). Recent statistics indicate that approximately $17 \%$ of all children and adolescents in the United States are affected by obesity (Centers for Disease Control and Prevention [CDC], 2016). Globally, the trajectory of childhood obesity is steadily increasing and is cited as one of the most "serious public health challenges of the 21st century" (World Health Organization [WHO], 2017). DeOnis, Blossner, and Borghi (2010) noted that if the obesity epidemic continues, nearly $9 \%$ of all preschool aged children around the world will be considered obese by 2020 (DeOnis, Blossner, \& Borghi, 2010).

One of the causes of obesity can be attributed to a child's lack of energy expenditure during the day. The average child sits for approximately 8.5 hrs each day (McManus et al., 2015). When a child's energy expenditure is not equal to energy intake, weight gain is inevitable. The energy balance can only be recovered through increased physical activity and healthy eating behaviors (Ling et al., 2014). Fernandes and Sturm (2011) examined the effect of physical activity at school on obesity prevention among 8,246 elementary students in 970 schools. Initially, body mass index (BMI) was calculated using each participant's height and weight. Each participant's teacher reported the frequency of physical education classes and recess. The amount of time each student participated in physical activity at school was then calculated. Data was collected periodically throughout the study, and results indicated that meeting the National Association of Sport and Physical Education's (NASPE) recommended time for recess "was associated with a decrease of 0.74 BMI percentile units" (Fernandes\& Sturm, 2011, p. 178). Thus, providing evidence to suggest that reducing physical activity at school can have a detrimental effect on elementary students' overall health.

\section{Recess as a mental break}

In addition to the social, academic, and physical reasons for providing elementary students with daily recess, people of all ages and in all professions benefit from breaks in their daily routine. According to Jarrett (2002), breaks are necessary for "satisfaction and alertness" (p. 2). Studies have also shown that short, structured breaks throughout the school day can improve physical activity levels, academic achievement, and concentration (Pelligrinini, Huberty, \& Jones, 1995; Caterino \& Polak, 1999; Barr-Anderson et al., 2011). One of the most critical aspects of recess is that it provides a break for elementary students in the day's routine. This break in routine can also be described as a "period of interruption" (Ramstetter et al., 2010 , p. 522). A period of interruption followed by a period of concentrated instruction is necessary for optimal cognitive processing in children (Ramstetter et al., 2010). When recess is provided as an unstructured break during the school day, the stresses and distractions that normally interfere with cognitive processes are diminished.

It is important to note that transitioning from one academic subject to another does not provide a cognitive or physical break (Barros et al., 2009). Only the unstructured free time that recess can provide, affords elementary students the opportunity for mental change and physical release. The benefits that come from this energy release reach far beyond a break from rigorous academic work and cognitive processing, as they have the potential to improve many aspects of the classroom (Barros et al., 2009).

As aforementioned, research continually indicates that physical activity has a positive impact on the academic, social and physical development of children. Taking this into account, the researchers' anecdotal observations in the field revealed that elementary students became increasingly off-task as recess drew closer and increasingly ontask after recess breaks. This evidence led the researchers to believe that studying the effects of recess on fifth grade students' time on-task in the classroom would be relevant and beneficial to elementary educators, administrators, policymakers, parents, and students. The present study aimed to address the following research questions:

1. Do on-task behaviors in the classroom increase or 
decrease after a 25 -minute period of recess?

2. Are the average minutes of on-task behaviors higher before or after recess?

3. Are the average minutes of off-task behaviors higher before or after recess?

\section{Method}

\section{Participants and setting}

This quantitative study examined the effect of recess on fifth grade students' time on-task in an elementary classroom. The present study took place in a fifth grade general education classroom in Northwest Mississippi. Participants were selected through non-probability purposive sampling and were inclusive of six female students and six male students, ages 10-12. Ethnicities of the participants were $66.7 \%$ Caucasian, 25\% African American, and $8.3 \%$ biracial. Participants involved in this study exhibited a wide range of ability levels as determined by their academic achievement. Academic achievement is representative of performance-based outcomes that identify the extent to which a student has met specific learning goals within the context of the learning environment. For the present study, academic achievement levels were determined by analyzing data from a formal standardized test entitled STAR that assessed both reading and mathematics skills. According to the criterion for the STAR assessments, $37.5 \%$ of the participants tested above grade level, $30.8 \%$ of the participants tested at grade level, and $31.7 \%$ of the participants tested below grade level. Prior to the study, consent was obtained from the classroom teacher, librarian, and art teacher to conduct observations in their classrooms. Parental consent and children's assent was not required, as there were no interactions with the participants during observations and no interventions were implemented.

\section{Instrument and observations}

An on-task and off-task frequency chart was utilized to document observations of participants' on- and/or offtask behaviors in the classroom prior to and following a 25-minute recess period (See Appendix A). The whole interval recording (WIR) protocol was utilized within the on- and off-task frequency chart to collect data, wherein the behavior that occurred during each time interval was recorded (Fisk \& Delmolino, 2012). This type of data collection system is known as discontinuous, as it divides the observation into equal duration intervals and notes the occurence or nonoccurence of a behavior within a given interval (Mudford, Taylor, \& Martin, 2009). The reserachers chose WIR by utilizing a guide Fisk and Delmolino (2012) developed to aid reserachers in selecting valid and reliable measurement systems based on the current body of research and the context of their study. Space was allocated in the task frequency chart for participant observations, six male and six female. Twelve observations were completed over a six week period from September 12, 2016 - October 19, 2016 on Mondays and Wednesdays for 30 minutes during the morning. The observations took place prior to recess in a fifth grade classroom and after recess in the school library or with the art teacher in the regular academic classroom. This type of observation is known as a controlled structured observation, as the observations were completed under the same conditions during each session and could be easily replicated. The observer did not have contact or interaction with the subject, as the sole intent was to observe behaviors in the most natural environment possible. Systematic time sampling was uti- lized during observations to acquire different samples of behavior at predetermined time intervals over the course of the observations. Sytematic time sampling, as opposed to random time sampling, enables observations to be generalized during the time in which the observation occurred (Bakeman, 1997).. Observations were divided into 5-minute intervals, wherein each 5-minute time interval included two codes that represented on-task or off-task behaviors. These behaviors were documented during the 5-minute time intervals for each participant. The list of on- and off-task behaviors observed for during this study were derived from the literatüre, wherein the most common recurring on- and off-task behaviors in the classroom setting were identified. Moreover, behaviors on the onand off-task lists were based on both quantitiative and qualitative studies noted in the literatüre that addressed actively engaged behaviors (on-task) which were correlated with student productivity and disruptive classroom behaviors (off-task) which were connected to less productive students (Dalton, Martella, \& Marchand-Martella, Rathvon, 1990; Sun \& Shek, 2012). The behaviors observed for included, but were not limited to the following:

\section{ON (on-task)}

- answering questions asked by teacher;

- looking at or writing on academic materials;

- receiving assistance from teacher or teacher's assistant;

- raising a hand and waiting to be called on;

- reading a book when finished with work; and

- looking at teacher or speaker.

OFF (off-task)

- playing with materials;

- staring into space/looking around class/stretching;

- laying head down;

- scribbling on paper;

- talking to a classmate about non-academic matter;

- talking to the teacher when not asked a question

- singing or talking aloud to oneself; and

- out of seat or walking around class without permission.

\section{Analyses}

During each observational period, the code that correlated with the participant's behavior for each 5-minute interval was circled. The code was determined by analyzing the behavior that was exhibited a majority of the 5-minute time interval. Upon final data collection, descriptive and inferential statistics were utilized to summarize the data sets. Two double bar graphs were created to display the average number of minutes each participant spent ontask and off-task prior to and after recess. The average number of minutes each participant spent on-task before recess and after recess was also converted to percentages and used to create a table that identified each participant's average percentage of time on-task before recess, average percentage of time on-task after recess, and average increase in time on-task from before to after recess. The double bar graphs and table were then compared to determine the overall increase or decrease that recess had on fifth grade students' time on-task in the classroom. Additionally, a paired samples t-test was completed to determine if the difference in increase of time on-task prior to and following recess were statistically significant. One of the assumptions of the paired t-test is that the two groups are normally distributed. Thus, the Shapiro-wilk test was utilized to test for normality. 


\section{Results}

Even though time allocated for recess in elementary schools has decreased across the United States (Hausenblas \& Rhodes, 2016), the justification for educational policy may rest on the assumption that reducing recess time increases instructional time, therefore improving academic performance. On the contrary, the present study's findings indicate that including recess in a school day's allocated time schedule in fact, increases time on-task. What is known from research is that time on-task is a strong indicator of academic engagement and achievement. Thus, this study adds to the breadth of research that argues recess should be included as a vital component of an elementary child's school day.

\section{Results for research question 1}

Results revealed that each of the 12 participant's average time on-task increased from before recess to after recess (See Table 1). Student 5 had the greatest increase in time on-task, from $20.8 \%$ time on-task prior to recess to $60.4 \%$ time on-task after recess. Student 2 showed the lowest percentage of time on-task before recess (18.7\%) and remained at the lowest percentage of time on-task after recess (56.2\%). However, this student showed great improvement in time on-task following recess (37.5\%). Student 3 displayed the smallest amount of increase in time on-task, from $64.5 \%$ before recess to $75 \%$ after recess. Though there was not a large increase in time ontask, this participant had the highest percentage of time on-task before recess and still showed an improvement in time on-task behaviors immediately following a period of recess. The overall average increase for all participants in time on-task from before recess to after recess was $33.7 \%$.

\section{Results for research question 2}

During the 30 minute period following recess, $100 \%$ of the participants spent more time on-task than off-task (See Figure 1). Only one participant (Student 3) had a less difference between the average amount of time spent ontask and off-task during the period of time immediately following recess. Student 3 spent 19.375 minutes on-task before recess and 22.5 minutes on-task following recess. This is a 3.125 minute increase in time on-task from before recess to after recess.

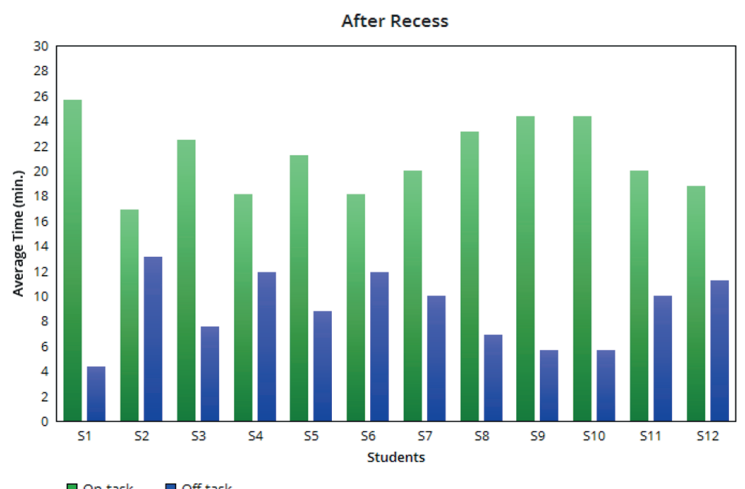

Figure 1. Participants' average time on-task and average time off-task after a period of recess.

\section{Results for research question 3}

Results also indicated that only two of the twelve participants observed, Student 3 and Student 9, spent more time on-task than off-task during the period of observation before recess (See Figure 2). Only two more of the twelve participants observed, Student 1 and Student 10 spent near equal amounts of time on-task and off-task. Student 1 spent $47.9 \%$ of time on-task and $52.1 \%$ of time off-task, and Student 10 spent $45.8 \%$ of time on-task and $54.2 \%$ of time off-task. Even though the amounts of time these two participants spent on-and off-task were similar, Student 1 spent 1.25 more minutes off-task than on-task, and Student 10 spent 2.5 more minutes off-task than ontask. The remainder of the twelve participants spent more time off-task than on-task on average during the period of observation before recess. In summary, $83.3 \%$ of the participants observed in the fifth grade classroom spent more time off-task than on-task during the 30 minutes prior to recess.

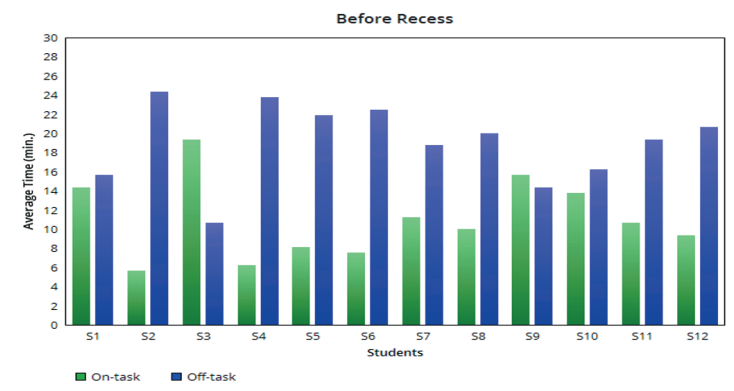

Figure 2. Participants' average time on-task and average time off-task before a period of recess.

\section{Paired t-test}

A paried samples t-test was completed to compare the means of time on-task before and after recess for a single group. Prior to completing the paired t-test, a Shapiro-wilk test was conducted to test for normality of the data. Results indicated that $p>.05$, indicating that the data was normal. Results of the paired-samples t-test revealed that the mean time on-task before recess $(M=36.59, S D=13.70)$ varied from after recess $(M=70.27, S D=9.61)$ at the .05 significance level $(t=13.17, d f=11, n=12)$ (See Table 1).

Table 1. Participants' average time on-task before recess, average time on-task after recess, and average increase in time on-task.

\begin{tabular}{rrrr}
\hline & $\begin{array}{r}\text { Before Recess } \\
\text { Average time } \\
\text { on-task }\end{array}$ & $\begin{array}{r}\text { After Recess } \\
\text { Average time } \\
\text { on-task }\end{array}$ & $\begin{array}{r}\text { Average } \\
\text { increase in } \\
\text { time on-task }\end{array}$ \\
\hline S1 & $47.9 \%$ & $85.4 \%$ & $37.5 \%$ \\
\hline S2 & $18.7 \%$ & $56.2 \%$ & $37.5 \%$ \\
\hline S3 & $64.5 \%$ & $75 \%$ & $10.5 \%$ \\
\hline S4 & $20.8 \%$ & $60.4 \%$ & $39.6 \%$ \\
\hline S5 & $27 \%$ & $70.8 \%$ & $43.8 \%$ \\
\hline S6 & $25 \%$ & $60.4 \%$ & $35.4 \%$ \\
\hline S7 & $37.5 \%$ & $66.6 \%$ & $29.1 \%$ \\
\hline S8 & $33.3 \%$ & $77 \%$ & $43.7 \%$ \\
\hline S9 & $52 \%$ & $81.2 \%$ & $29.2 \%$ \\
\hline S10 & $45.8 \%$ & $81.2 \%$ & $35.4 \%$ \\
\hline S11 & $35.4 \%$ & $66.6 \%$ & $31.2 \%$ \\
\hline S12 & $31.2 \%$ & $62.5 \%$ & $31.3 \%$ \\
\hline
\end{tabular}

Note: Data analysis showed that when the difference in mean time on-task prior to and following recess were compared $(p=.00001)$, the results were statistically significant, $p<.05$.

To conclude, when the behaviors of participants were observed prior to a period of recess $100 \%$ of the participants 
displayed an increase in time on-task. Participants spent, on average, between 3.125 and 13.125 more minutes ontask in the classroom after a period of recess. Therefore, the findings from this study indicate that a 25 -minute period of recess significantly increased fifth-grade students' average time on-task in the classroom.

\section{Discussion}

Similar to results of previous quantitative studies (Jarrett, 2002; Pellegrini \& Bohn, 2005; Ramstetter et al., 2010), this study supports the theory that short breaks which include physical activity during the school day enable students to remain on-task for longer periods of time. A study by Foran, Manion, \& Rutherford (2017) also found that teachers perceived students to be more focused after participating in physical activity. While numerous studies have been conducted that indicate students who are physcially active during the school day earn higher grades, are more focused, and perform better on achievement tests (Hillman, Erickson, \& Kramer, 2008; Rasberry et al., 2011), much less is known about why this actually occurs. To address the "why," researchers have recently begun to examine the changes in the overall physiology of the brain that occurs when children participate in physical activity. Recent brain imaging technology has enabled reserachers to examine children's brain malleations during physical activity and correlate them to a child's learning and development (Hillman, Erickson, \& Kramer, 2008). Ploughman (2008) also noted that changes in the brain, such as increased neurotransmitters identified through EEG tests, oxygen saturation, and growth in the brain-derived neurotropic factor are all correlated to cognitive development for children. Thus, this provides evidence to suggest that the changes in brain physiology that occur when students participate in physical activity at school, such as recess, have the ability to improve cognitive functions needed for success, such as attention and focusing on tasks in the classroom. Therefore, recess needs be considered an essential element of the school day and should be taken into consideration when daily schedules are developed in elementary schools. Future research should take this into consideration when addressing the connections between children's physical activity, changes in brain physiology and performance in the classroom. Contrary to arguments utilized by those who eliminate recess time, findings of this study indicate that recess positively affected the ontask behaviors of fifth grade students in the classroom.

\section{Limitations}

The effect of recess on each participant's time on-task indicated statistically significant outcomes, however, there are a number of limitations that may have factored into the results. One of the limitations was the location of the school at which participants were observed and the time of year when the research was conducted. The research was conducted in the state of Mississippi, during the months of September and October. These months are particularly warm, which may have had an effect on the findings by altering participants' activity levels at recess. Another limitation of this study was the subject matter participants learned during observational periods, both before and after recess. On Mondays, participants attended a library class following recess, and on Wednesdays, participants attended an art class following recess. Studying different subjects could have influenced participants to demonstrate more on-task or off-task behaviors depending on interest level of the subject. A third limitation of this study is the time of day in which students participated in a period of recess. If recess had been offered earlier or later in the school day, the findings of this study could have been different. Furthermore, this study only examined the ontask and off-task behaviors of twelve fifth grade students. A larger sample size of fifth grade students may aid in further validating the findings of the present study.

Observational data was collected while the researcher stood in the back of the classroom to provide the least amount of distraction possible. The purpose of being minimally distracting was to guarantee that participants' on-task or off-task behaviors were genuinely reflective of their typical classroom behavior and were not affected by the observations that took place. If the observations did produce distractions, they would be considered a limitation of the research study. The amount of recess time participants were provided is another limitation of this research study. Participants' daily schedule allocated 25 minutes of recess, but on occasion participants would receive less than or more than 25 minutes of recess depending on when assignments were completed, weather conditions, and other varying circumstances.

Lastly, the variety of assignments that participants completed during each observation period before and after recess could be considered a limitation. Some tasks could be considered much more engaging and interactive, which could cause participants to demonstrate more on-task behaviors. These engaging or interactive tasks included cooperative learning activities or timed multiplication tests. Conversely, some tasks that participants were assigned could be considered more mundane and required a higher level of self-discipline from participants to complete, such as listening to the teacher read texts aloud or completing worksheets. This could have caused participants to demonstrate more off-task behaviors.

\section{Conclusion and recommendations}

Findings from this study indicated a positive association between allocating time for recess and on-task classroom behaviors. However, future research might include a larger sample size with a similar design. It would also be advantageous to include a group of more varied participants to provide further validation of this study. Other opportunities for future research may examine the effects of recess when provided to students at different times throughout the school day, the effects that longer or shorter recess periods have on time on-task, how recess affects students in different grade levels, and/or how the effects of recess may differ between gender.

In summary, this study provides a small, albeit significant insight into the behavioral and subsequently academic advantages of providing elementary students with a recess break during the school day. Findings demonstrated that recess significantly increased on-task behaviors of fifth grade students in an elementary classroom. While it is recommended that children receive at least $60 \mathrm{~min}$ utes of physical activity each day, the stark reality is that many students in countries across the world, including the United States, receive short recess breaks or no breaks at all due to educational policies that have increased instructional time. Thus, it is critical that administrators, educators, and policymakers find the intricate balance between allocating time for recess and academics to ensure that all elementary school children are afforded the opportunity to succeed at their highest potential.

\section{References}

Bakeman, R. (1997). Observing interaction: A sequential analysis. Cambridge, MA: Cambridge University Press. 
Baker, D. P., Fabrega, R., Galindo, C., \& Mishook, J. (2004). Instructional time and national achievement: Cross-national evidence. Prospects: Quarterly Review of Comparative Education, 34(3), 311-334.

Barros, R. M., Silver, E. J., \& Stein, R. E. (2009). School recess and group classroom behavior. Pediatrics, 123(2), 431-436.

Barr-Anderson, D. J., Au-Young, M., Whitt-Glover, M. C., Glenn, B. A., \& Yancey, A. K. (2011). Integration of short bouts of physical activity into organizational routine: A systematic review of the literature. American Journal of Preventive Medicine, 40(1), 7693.

Berliner, D. C., \& Tikunoff, W. J. (1976). The california beginning teacher evaluation study: Overview of the ethnographic study. Journal of Teacher Education 27(1), 24-30, doi:10.1177/002248717602700107.

Brusseau, T. A., \& Hannon, J. C. (2015). Impacting children's health and academic performance through comprehensive school physical activity programming. International Electronic Journal of Elementary Education, 7(3), 441-450.

Burriss, K., \& Burriss, L. (2011). Outdoor play and learning: Policy and practice. International Journal of Education Policy and Leadership, 6(8), 1-12.

Caterino M. C. \& Polak E. D. (1999). Effects of two types of activity on the performance of second-, third-, and fourth-grade students on a test of concentration. Perceptual and Motor Skills, 89(1), 245-248.

Centers for Disease Control and Prevention. (2016). Childhood obesity facts. Retrieved from https://www. cdc.gov/obesity/data/childhood.html.Accessed January 29, 2017.

Center on Education Policy. (2008). Instructional time in elementary schools: A closer look at changes for specific subjects. Retrieved from http://www.cepdc.org/displayDocument.cfm?DocumentID= 309 . Accessed February 18, 2017.

Chin, J. J., \& Ludwig, D. (2013). Increasing children's physical activity during school recess periods. American Journal Of Public Health, 103(7), 1229-1234.

Chang, R., \& Coward, C. L. (2015). More recess time, please Ensuring that children have multiple breaks from learning each day is a core tenet of education in shanghai. Phi Delta Kappan, 14-17.

Dalton, T., Martella, R. C., Marchand-Martella, N. E. (1999). The effects of a self-management program in reducing off-task behavior. Journal of Behavioral Education 9(3), 157-176.

De Onis, M., Blossner, M., \& Borghi, E. (2010). Global prevalence and trends of overweight and obesity among preschool children. American Journal of Clinical Nutrition, 92, 1257-64.

Donnelly, J. E., \& Lambourne, K. (2011). Classroom-based physical activity, cognition, and academic achievement. Preventive Medicine, 52(2011), S36-S42.

Erwin, H. E., Ickes, M., Ahn, S., \& Fedewa, A. (2014). Impact of recess interventions on children's physical ac-
tivity-A meta-analysis. American Journal of Health Promotion, 28(3), 159-167.

Fernandes, M., \& Sturm, R. (2011). The role of school physical activity programs in child body mass trajectory. Journal of Physical Activity and Health, 8(2), 174-181.

Fiske, K., \& Delmolino, L. (2012). Use of discontinuous methods of data collection in behavioral intervention: Guidelines for practitioners. Behavior Analysis Practice, 5(2), 77-81. doi: 10.1007/BF03391826

Hausenblaus, H. \& Rhodes, R. E. (2016). Exercise psychology: Physical activity and sedentary behavior. Burlington, MA: Jones and Bartlett Learning.

Hillman, C., Erickson, K. I., \& Kramer, A. F. (2008). Be smart, exercise your heart: Exercise effects on Brain and cognition. Nature Reviews Neuroscience, 9(1), 58.

Jarrett, O. S. (2002). Recess in elementary school: What does the research say? Retrieved from http://files. eric.ed.gov/fulltext/ED466331.pdf. Accessed January 16, 2017.

Karweit, N., \& Slavin, R. E. (1981). Measurement and modeling choices in studies of time and learning. American Educational Research Journal, 18(2), 157-171.

Ling, J., King, K. M., Speck, B. J., Kim, S., \& Wu, D. (2014). Preliminary assessment of a school-based healthy lifestyle intervention among rural elementary school children. Journal Of School Health, 84(4), 247-255.

London, R., Westrich, L., Stokes-Guinan, K., \& McGlaughlin, M. (2015). Playing fair: The contribution of high-functioning recess to overall school climate in low-income elementary schools. Journal of School Health, 85(1), 53-60.

McManus, A. M., Ainslie, P. N., Green, D. J., Simair, R. G., Smith, K., \& Lewis, N. (2015). Impact of prolonged sitting on vascular function in young girls. Exercise Physiology, 100(11), 1379-1387.

Mudford, O. C., Taylor, S. A., \& Martin, N. T. (2009). Continuous recording and interobserver agreement algorithms reported in the Journal of Applied Behavior Analysis (1995-2005), Journal of Applied Behavior Analysis, 42(1), 165-169. doi: 10.1901/jaba.2009. 42-165

Ogden, C., \& Carroll, M. (2010). Prevalence of obesity among children and adolescents: United states, trends 1963-1965 through 2007-2008. Retrieved from https://www.cdc.gov/nchs/ data/hestat/ obesity_child_07_08/obesity_child_07_08.htm. Accessed February 18, 2017.

Pellegrini, A. D., \& Bohn, C. M. (2005). The role of recess in children's cognitive performance and school adjustment. Educational Researcher, 34(1), 13-19.

Pellegrini, A. D., Huberty, P. D., \& Jones, I. (1995). The effects of recess timing on children's playground and classroom behaviors. American Educational Research Journal, 32(4), 845-864.

Pellegrini, A. D., \& Smith, P. K. (1993). School recess: Implications for education and development. Review of educational research, 63(1), 51-67. 
Pennsylvania State Education Association. (2010). The power of a great education: PSEA's 20/20 vision for the future. Retrieved from https://www.psea.org/ vision/. Accessed March 4, 2017.

Ploughman, M. (2008). Exercise is brain food: The effects of physical activity on cognitivefunction. Developmental Neurorehabilitation, 11(3), 236-240.

Ramstetter, C. L., Murray, R., \& Garner, A. S. (2010). The crucial role of recess in schools. Journal of School Health, 80(11), 517-526.

Rathvon, N. W. (1990). The effects of encouragement on off-task behavior and academic productivity. $\mathrm{El}$ ementary School Guidance and Counseling, 24(3), 189-199.

Silva, E. (2007). On the clock: Rethinking the way schools use time. Washington, DC: Education Sector.

Springer, A. E., Tanguturi, Y., Ranjit, N., Skala, K. A., \& Kelder, S. H. (2013). Physical activity during recess in low-income third-grade Texas students. American Journal Of Health Behavior, 37(3), 318-324.

Sun, R., \& Shek, D. (2012). Student classroom misbehavior: An exploratory study based on Teachers' perceptions. The Scientific World Journal, Article ID 208908 1-8. doi: 10.1100/2012/208907.

World Health Organization. (2017). Global Strategy on Diet, Physical Activity, and Health. Retrieved from http://www.who.int/dietphysicalactivity/childhood/en/ 


\section{Appendix}

\begin{tabular}{|c|c|c|c|c|c|c|c|}
\hline \multirow[b]{2}{*}{ Student } & \multicolumn{7}{|c|}{$\begin{array}{c}\text { On-Task and Off-Task Behaviors } \\
\text { On-Task (ON) } \\
\text { Off-Task (OFF) }\end{array}$} \\
\hline & Minute 0 & Minute 5 & $\begin{array}{c}\text { Minute } \\
10\end{array}$ & $\begin{array}{c}\text { Minute } \\
15\end{array}$ & $\begin{array}{c}\text { Minute } \\
20\end{array}$ & $\begin{array}{c}\text { Minute } \\
25\end{array}$ & $\begin{array}{c}\text { Minute } \\
30\end{array}$ \\
\hline \multirow{2}{*}{ S1 } & ON & ON & ON & ON & ON & ON & ON \\
\hline & OFF & OFF & OFF & OFF & OFF & OFF & OFF \\
\hline \multirow{2}{*}{ S2 } & ON & ON & ON & ON & ON & ON & ON \\
\hline & OFF & OFF & OFF & OFF & OFF & OFF & OFF \\
\hline \multirow{2}{*}{ S3 } & ON & ON & ON & ON & ON & ON & ON \\
\hline & OFF & OFF & OFF & OFF & OFF & OFF & OFF \\
\hline \multirow{2}{*}{ S4 } & ON & ON & ON & ON & ON & ON & ON \\
\hline & OFF & OFF & OFF & OFF & OFF & OFF & OFF \\
\hline \multirow{2}{*}{ S5 } & ON & ON & ON & ON & ON & ON & ON \\
\hline & OFF & OFF & OFF & OFF & OFF & OFF & OFF \\
\hline \multirow{2}{*}{ S6 } & ON & ON & ON & $\mathrm{ON}$ & ON & ON & ON \\
\hline & OFF & OFF & OFF & OFF & OFF & OFF & OFF \\
\hline \multirow{2}{*}{ S7 } & ON & ON & ON & ON & ON & ON & ON \\
\hline & OFF & OFF & OFF & OFF & OFF & OFF & OFF \\
\hline \multirow{2}{*}{ S8 } & ON & ON & ON & ON & ON & ON & ON \\
\hline & OFF & OFF & OFF & OFF & OFF & OFF & OFF \\
\hline \multirow{2}{*}{ S9 } & ON & ON & ON & ON & ON & ON & ON \\
\hline & OFF & OFF & OFF & OFF & OFF & OFF & OFF \\
\hline \multirow{2}{*}{$\mathrm{S} 10$} & ON & ON & ON & ON & ON & ON & ON \\
\hline & OFF & OFF & OFF & OFF & OFF & OFF & OFF \\
\hline \multirow{2}{*}{$\mathrm{S} 11$} & ON & ON & ON & $\mathrm{ON}$ & ON & ON & ON \\
\hline & OFF & OFF & OFF & OFF & OFF & OFF & OFF \\
\hline \multirow{2}{*}{$\mathrm{S} 12$} & ON & ON & ON & ON & ON & ON & ON \\
\hline & OFF & OFF & OFF & OFF & OFF & OFF & OFF \\
\hline
\end{tabular}

